Books, videos, cd-roms, dvds and any other relevant items submitted for a review in the BDJ should be addressed to:

Mike Grace, Editor, British Dental Journal, 64 Wimpole Street WIG 8YS
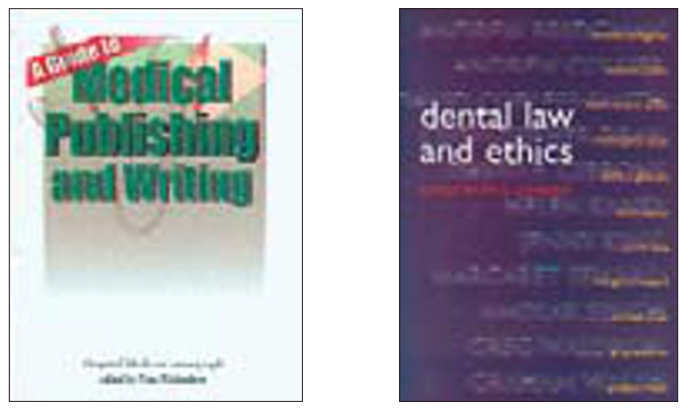

\section{A guide to medical publishing and writing}

\author{
P. Richardson \\ Salisbury: Quay books / Mark Allen, 2002 \\ price $€ 10.99$, pp145 \\ ISBN 1856422224
}

Those involved in editing, writing and reviewing papers for journals often find they have very little help in how to do these things, other than anecdotal comments from colleagues and the process of learning by 'getting it wrong'. This book is here to help them.

On first glance I felt this small book seems to be trying to be all things to all people involved in medical publishing because of the large number of topics covered in an extremely short space. But as I began to read through it I became impressed with the fact that whilst the book is brief, it has filtered the truly relevant from the rest.

The book consists of a collection of articles from hospital medicine covering publishing, writing and accessing information. Because of this, it lacks consistency in style and content, and there is a tenuous thread to the book around getting published. This thread is truly tenuous, as the movement from topic to topic relies entirely on the topics themselves rather than an apparently overt attempt to structure the book for the reader. Thus it is a book for dipping into rather than reading in one sitting.

There are 15 chapters written by 15 contributors, all experts in their field. Some of the articles are quite lengthy, others short and punchy. Some would appeal to academics and researchers, others to educators while others seem to be aimed at anyone. The book has a UK flavour and, although written for general medical practitioners, applies equally to dentists.

There are 145 pages but the book is pocket-sized (easily fitting into the pocket of a hospital white coat) and each chapter has a useful summary of key points at the end of the text. There is a mix of references, further reading and useful addresses, depending on the author and topic.
As an editor myself I enjoyed the advice throughout on how researchers should approach writing up their research (including the vital guidance to check proofs scrupulously for errors) and I really wish letter writers (for publication) knew the advice in the chapter on How to write a critical letter and respond to one. I also loved the help given on effective writing in Table 4.1 which all writers (including myself) should have framed on the wall in front of them when they write. Perhaps the hardest to follow is the rule of restricting sentences to 15-20 words. I must take another look at some of my own editorials.

All in all this is a gem of a book for those involved in any editing or writing. It may not appear to contain much but the advice on writing is solid, short and essential. Some of the other chapters are of limited interest only but the core advice is invaluable for anyone involved in publishing.

\section{Grace [BR5063]}

\section{Dental law and ethics}

PLambden (ed)

Oxford: Radcliffe Medical Press, 2002 price $€ 29.95$, pp 182

ISBN 1857759117

This book comprises 14 chapters written by 11 distinguished contributors. Given the number of authors and the frequent overlap of their particular subjects, the editor acknowledges that there is some duplication. However, the approach does permit each chapter to stand alone to a certain degree.

The book opens with a chapter on the General Dental Council which considers its structure, remit and procedures, along with professional standards. Initially this seems an odd way to start, given the deeper discussion of ethical principles and approaches dealt with in detail later. However, there are many subsequent references to the GDC and, on balance, it is helpful to have an understanding of the council from the outset. It was inevitable that this chapter would be somewhat out of date at publication despite the author seeking opportunities to anticipate the current changes emerging in the GDC.

In a chapter on rights and responsibilities in dentistry the ethical principles underpinning healthcare along with the duties of dentists are discussed in broad terms, highlighting changes in attitudes and approach. The professional duties of dentists are outlined in what becomes a rather mechanistic chapter, using an illustrative approach that clearly cannot be comprehensive. Importantly, whistle blowing and professional health issues are discussed.

A clearly argued and stimulating chapter on resource allocation and business ethics is followed by one considering the changes occurring in the clinical relationship, although parts of this excellent chapter may be difficult for some undergraduates. A full discussion of the ethical and legal aspects of confidentiality follows.

The changing approaches to consent are considered in detail from ethical and legal points of view in a superb chapter that is structured, argued and referenced well. A second chapter dealing with informed consent, although good, adds little save for a deeper discussion of the disclosure of risks. A single all-embracing chapter might have been more appropriate.

A series of helpful chapters follow in which more specialised aspects of the subject are considered, including dental care for children and mentally disabled adults, in which, issues of consent and best interests are central. A chapter on practising in the NHS gives a helpful overview that will be of particular significance to most senior undergraduates and VDPs. There is a concise account of negligence and litigation which includes reference to the new Civil Procedure Rules. Legal considerations in Scotland have a separate chapter. The book closes with a presentation of the ethical and legal aspects of medical and dental research.

Overall this is an excellent book, of particular value to undergraduates and those in the early stages of their dental careers. I have been pleased to commend it to my own undergraduate students.

J. Cunningham [BR5055] 